\title{
Revisitando a acessibilidade a partir do modelo social da deficiência: experiências na educação superior
}

\author{
Jackeline Susann Souza da Silva*
}

\section{Resumo}

No começo deste século, a acessibilidade tornou-se uma determinaçâo legislativa que visa eliminar barreiras nos diferentes espaços sociais para pessoas com deficiência e mobilidade reduzida. Na educação superior, a acessibilidade é condição fundamental para que o estudante com deficiência ingresse, permaneça e participe das atividades acadêmicas. Este artigo tem como objetivo analisar a acessibilidade na experiência de estudantes com deficiência da educação superior. Para tanto, utilizamos a metodologia de Estudos de Caso com a técnica shadowing, a observação e a entrevista semiestruturada para investigar a unidade de estudo: experiência de acessibilidade de seis estudantes com deficiência, três mulheres e três homens. Os principais achados da pesquisa indicam que a acessibilidade ainda não é aplicada como um direito, mas como uma assistência individual e, justamente por isso, prevalece na educação superior a adaptação do estudante com deficiência sem modificação da estrutura institucional, isto é consequente da visão médico-patológica sobre estes estudantes, que não são percebidos como sujeitos de direitos.

Palavras-chave: Deficiência; Acessibilidade; Educação Superior.

* Mestre em Educação pela Universidade Federal da Paraíba, João Pessoa, Paraíba, Brasil. 


\section{Revisiting accessibility from the perspective of the social model of disability: students' experiences in higher education}

\section{Abstract}

At the beginning of this century, accessibility has become a legislative determination that seeks to eliminate barriers in different social spaces for people with disabilities and reduced mobility. In higher education, accessibility is an essential condition for the student with disabilities joining, staying and participating in academic activities. This article aims to analyze the accessibility in the experience of students with disabilities in higher education. For this, we use the methodology of case studies with the shadowing technique, observation and semi-structured interviews to investigate the study unit: accessibility experience of six students with disabilities, being three women and three men. The main research findings indicate that accessibility is not yet applied as a right but as individual assistance and, precisely because of this, in higher education the adaptation of students with disabilities often happens without the modification of the institutional structure. This is a consequence of the medical and pathological view of these students, who are not perceived as individuals with rights.

Keywords: Disabilities; Accessibility; Higher education.

\section{Introdução}

Este artigo tem como objetivo identificar experiências de acessibilidade ou barreira de estudantes com deficiência no vestibular e durante a formação universitária. A acessibilidade é a base da participação social e do exercício da cidadania (ONU, 2006) por meio do direito de acesso, por exemplo, aos ambientes, à educação, à saúde, ao lazer, ao emprego e à convivência. Considerando a importância deste conceito no contexto da educação superior para coesão social e democratização do saber científico, a estrutura da universidade é colocada em questáo quando viola o direito de acesso a determinados grupos, particularmente aqueles que são oriundos de camadas sociais vulneráveis, grupos que sofrem risco de não participação e de não acesso aos serviços e bens sociais (ZAGO, 2006).

A exclusão do/no ensino superior foi construída sob a égide dos princípios meritocráticos, da competitividade e da seletividade que a justifica como algo 'natural' e mantém fora deste nível de formação supostamente aqueles que não são 'igualmente capazes' de obter aprovação por meio de exames vestibulares (RODRIGUES, 2006; SILVA, 2014). Esta seletividade se torna um grave problema porque não se contesta a estrutura universitária, mas a condição individual do candidato. Desta forma, o direito de acesso em condições de igualdade com os demais (BRASIL, 1988, art. $5^{\circ}$; ONU 2006, Art. $1^{\circ}$ ) é sistematicamente violado na educação superior por sua própria concepção pedagógica e administrativa, como mostra a presente pesquisa. 
Historicamente, as pessoas com deficiência foram excluídas dos sistemas educacionais, por isso ainda é crescente e, ao mesmo tempo pouco, o número de ingressantes desta população nos cursos superiores. Caracterizando esta realidade, a revisão de literatura de produçóes brasileiras - publicadas no banco de dados da ANPED ${ }^{1}$ e da $\mathrm{CAPES}^{2}$ a partir do uso das palavras-chave acessibilidade, educação superior e pessoa com deficiência ${ }^{3}$ - evidencia o aumento sistemático da atenção de pesquisadoras e pesquisadores com o estudo sobre a formação na educação superior de estudantes com deficiência. No recorte de 50 trabalhos, 17 anunciaram a acessibilidade como categoria-chave (OLIVEIRA, 2003; SASAZAWA, 2005; LAMÔNICA et al. 2008; FERNANDES, 2009; SOUZA, 2010; ALBINO, 2010; GREGIO, 2011; SILVA, 2011; MELO, 2011; TAVARES, 2011; MARTINS, 2011; MAGRI, 2011; MARGON, 2012; SANTOS, 2012; BARDI, 2012; CARVALHO, 2012; JUNIOR, 2012).

A acessibilidade aparece nas pesquisas como um direito dos estudantes com deficiência por fazer parte do marco político-legal nacional (BRASIL, 2000; 2004; 2005; 2009; 2011) e ser um elemento fundamental na construção de sistemas de ensino inclusivo. No entanto, os resultados dessas investigaçôes indicam que pessoas com deficiência enfrentam barreiras distintas para ingressar, permanecer e concluir o ensino superior. Por suposição, isso é decorrente da história de exclusão e assujeitamento social (SOARES, 2010) que limita as chances de desenvolvimento humano desse grupo (OLIVEIRA, 2003; SASAZAWA, 2005; LAMÔNICA et al. 2008; FERNANDES, 2009; SOUZA, 2010).

Segundo Soares (2010, p. 14) as pessoas com deficiência estão condicionadas a "invisibilidade social desde tenra idade e são infantilizadas quando jovens e adultos por aqueles que as cercam. Isso intensifica sua exclusão (social, relacional e educacional) e gera restriçóes no acesso a experiências em novos espaços sociais". Dessa forma, quando uma pessoa com deficiência decide seguir carreira universitária, ela precisa ser resiliente (FARIAS, 2011) para enfrentar o ciclo de impossibilidades (FERREIRA, 2004) presente neste processo, por exemplo, os obstáculos no acesso à informação acessível sobre os cursos universitários; as barreiras nos procedimentos necessários para a realizaçáo do vestibular e, mais tarde, todos os entraves durante a formação acadêmica que são gerados pela falta de acessibilidade nas diferentes dimensóes desta experiência (SOUZA, 2010; SILVA, 2011). Assim, os resultados das pesquisas revisadas corroboram que a única opção do estudante com deficiência é a resiliência cotidiana (FARIAS, 2011) - luta muitas vezes isolada - para conseguir ingressar, permanecer e se desenvolver no curso superior (MAGRI, 2011; MARGON, 2012; SANTOS, 2012; BARDI, 2012; CARVALHO, 2012; JUNIOR, 2012).

$\mathrm{Na}$ literatura, o conceito de acessibilidade é desenvolvido como um conhecimento interdisciplinar que se fundamenta nos campos das Ciências Sociais, Humanas e Exatas, por exemplo, Pedagogia, Direito, Arquitetura, Engenharia e Ciências da Computaçáo (LIPPO, 2012). Além da sua abrangência teórico-conceitual, a acessibilidade é um tema transversal na vida humana, independentemente da pessoa ter ou náo uma deficiência. No caso específico do grupo de pessoas com deficiência, a 
acessibilidade é um direito humano (BRASIL, 2000; 2004; 2005; 2009) porque é a condição sine qua non há o usufruto da sua dignidade: direito de ser livre, de fazer escolhas, de ir e vir, de comunicar, de conviver, entre outros direitos (BRASIL, 1988; ONU, 2006).

Nesta direção, esta pesquisa adota a perspectiva da deficiência defendida na Convenção sobre os Direitos das Pessoas com Deficiência que a declara como "um conceito em evolução", resultado da "interação entre pessoas com deficiência e barreiras devidas às atitudes e ao ambiente que impedem a plena e efetiva participação em igualdade de oportunidades com as demais" (ONU, 2006, Preâmbulo). Assim, a acessibilidade é analisada pelo prisma do modelo social (OLIVER, 1983) em que sua ausência é consequência de "uma estrutura dada pela opressão, pela inequidade e pela exclusáo" (COBOS, MORENO, 2014, p. 87), sendo a experiência da deficiência, portanto, implicada a diferentes obstáculos sociais e não a condição individual. Para ampliar a noção normativa da acessibilidade, esta pesquisa enfoca a abordagem teórico-metodológica pós-moderna em que se (des)constrói a experiência da deficiência a partir dos princípios culturais que sustentam os valores de capacidade, capacitismo e corponormatividade (MCRUER, 2006; MELLO, FERNANDES, 2013; MELLO, NUERNBERG, 2012).

Como um direito também das pessoas com deficiência, os espaços de excelência educacionais, como as universidades, necessitam incluir este grupo social para que essas pessoas participem e contribuam com o desenvolvimento científico, tecnológico e laboral em condiçóes de igualdade com os demais (BRASIL, 1988; ONU, 2006). Nesta linha, o Programa Incluir: Acessibilidade na Educação Superior, lançado pelo governo federal no começo deste século, tem como objetivo fomentar a criação de núcleos de acessibilidade nas universidades para a organizaçáo de açóes institucionais que visem eliminar barreiras pedagógicas, arquitetônicas, na comunicação e informação (BRASIL, 2003). Esta política de acessibilidade deu visibilidade aos processos de inclusão no nível de educação superior e também teve impacto social porque aumentou o número de matrícula de estudante com deficiência: no começo dos anos 2000 o número era de 2 mil estudantes com deficiência na educação superior, agora já no final da década passada esse número subiu para aproximadamente 20 mil ingressantes com deficiência, ou seja, um crescimento de 900\% (BRASIL/INEP, 2010). Ainda que o censo apresente dados animadores, o grau de instruçáo em nível superior de pessoas com deficiência chega somente a 6,66\%, número bastante reduzido para um grupo com grande representatividade no país: $24 \%$ da populaçáo brasileira se declara com deficiência (BRASIL/IBGE, 2010).

Para conhecer a aplicabilidade da política de acessibilidade na prática vivida por estudantes com deficiência, esta investigaçáo apresenta casos registrados em uma universidade do nordeste brasileiro. Deste modo, este artigo está estruturado da seguinte forma: na primeira seção, descreve-se o caminho metodológico adotado, com destaque ao uso da técnica shadowing. Na segunda seçáo, são narrados os dados coletados no campo a partir das respostas dos participantes, interaçóes, registros e da nossa atuação como sombra, interpretados à luz do referencial político-legal e da 
literatura delimitada na primeira fase da pesquisa. E, finalmente, na última seção, apresentam-se conclusóes do estudo e apontamentos para futuras investigaçóes.

\section{Método}

Para investigar a acessibilidade na educação superior, adotamos como metodologia o Estudo de Caso (LUCK, ANDRÉ, 1986). Delimitamos como caso ou unidade de estudo a experiência de acessibilidade ou/e inacessibilidade vivida por seis estudantes com deficiência em cursos de graduação. Esta metodologia oferece um conjunto de fontes de coletas de dados, por exemplo, observaçáo, entrevista, questionário, fotos e documentos (LUCK, ANDRÉ, 1986).

No âmbito da observação, destaca-se o uso da técnica shadowing - que significa sombrear, fazer sombra - ainda desconhecida nas pesquisas educacionais e pouco utilizada nas investigaçóes qualitativas no Brasil. Prova disso, é que em buscas online em periódicos nacionais encontramos somente seis trabalhos que utilizaram esta técnica (MCDONALD, 2005; ROSA, MEDEIROS, JUNIOR 2012; JUNIOR S/D; THERON, SAPPEY, 2012; DANTAS, 2011; SILVA, 2014). A técnica shadowing é o acompanhamento ininterrupto do participante no local comum da sua rotina. Neste caso, esta técnica serviu para identificar, refletir e interpretar as vivências de acessibilidade e barreira experienciadas pelos estudantes com deficiência na sala de aula, nos corredores, calçadas, restaurante universitário, laboratório de informática, sala de atendimento especializado, entre outros. Atuamos como sombra dos participantes em situaçôes que permitiram o aprofundamento da observação (THERON, SAPPEY, 2012). A shadowing não se restringe a uma situação específica, mas sim possibilita ao investigador "tornar-se a sombra de um sujeito [seguindo-o] em cada atividade cotidiana, inclusive as mais informais ou aparentemente não importantes, sem qualquer interrupção" (VERZELLONI apud JUNIOR, s/d, 12).

A coleta de dados com a técnica shadowing foi realizada durante um período da rotina acadêmica dos participantes, aproximadamente seis horas seguidas, com variaçóes do momento do dia conforme a agenda de cada estudante. Durante aplicabilidade da técnica, utilizamos um diário de campo com a finalidade de registrar impressôes, sentimentos, comentários e interpretações acerca do que vivenciamos no campo. A escrita no diário foi feita de forma livre e espontânea com o propósito de 'despertar' para aquilo que é consensual, contraditório, relevante e intrigante na interação com o ambiente e com os sujeitos participantes.

A entrevista semiestruturada foi aplicada antes da técnica shadowing com o propósito de conhecer elementos da história de vida dos participantes, por exemplo, dados relacionados à/ao renda, estado civil, moradia, acesso à tecnologia e internet, bem como para identificar situaçôes que revelam as condições/experiências de ingresso e permanência dos estudantes no curso superior. A entrevista ocorreu de forma individual, foi realizada na própria universidade investigada, durou aproximadamente 40 minutos e foi desenvolvida a partir de um roteiro com temáticas gerais sobre acessibilidade. Neste momento também utilizamos o diário de campo e o gravador de voz. Vale destacar que todas as transcriçóes das falas ocorreram a partir da escuta 
integral e logo depois da escuta ativa, caracterizando-se por cinco etapa principais: (1) escuta; (2) interpretação atenta; (3) seleção do conteúdo; (4) novamente escuta dos trechos selecionados e, por último, (5) descrição em detalhes das narrativas que tinham maior relevância para os objetivos desta pesquisa.

Por último, esta investigação utilizou a análise documental das normativas político-legais que fundamentam o direito à acessibilidade nas universidades brasileiras. Também foram analisados documentos institucionais que tratam da política de acessibilidade e registros gerais da coordenadoria de graduação sobre as demandas de estudantes com deficiência da instituição de educaçẫo superior investigada.

$\mathrm{Na}$ análise dos dados foi considerado o acesso à universidade - antes do vestibular e o vestibular - e experiências durante a formação universitária, tomando como base quatro tipos de acessibilidade (BRASIL, 2004; 2005; 2009): (1) acessibilidade arquitetônica e estrutural; (2) acessibilidade atitudinal; (3) acessibilidade informacional e comunicacional e (4) acessibilidade pedagógico-curricular. Os tipos de acessibilidade serviram de categoria de análise para sistematização e organização dos dados. Posteriormente, os dados foram analisados à luz do marco político-legal e dos referenciais teóricos adotados na fase inicial do estudo.

\title{
Resultados e interpretação dos dados
}

Os participantes desta pesquisa foram seis estudantes com deficiência matriculados em uma universidade federal do nordeste brasileiro. A lista abaixo descreve seus nomes fictícios, sexo, tipo de deficiência e curso superior:

\section{LISTA DOS PARTICIPANTES DA PESQUISA NOME | SEXO | TIPO DE DEFICIÊNCIA | CURSO}

\author{
1. Josefa: Feminino $\mid$ Deficiência Física |Licenciatura em Pedagogia \\ 2. Francisco: Masculino | Cego | Licenciatura em Pedagogia \\ 3. Fernanda: Feminino | Paralisia Cerebral | Letras-Português \\ 4. Bruno: Masculino | Cego | Bacharelado em Educaçáo Física \\ 5. Mel: Feminino | Surda | Ciência da Computaçáo \\ 6. Carlos: Masculino | Surdo | Curso de Física
}

Os participantes foram contatados por meio de correio eletrônico, no qual foi anexado uma carta-convite com informaçóes sobre o objetivo da pesquisa e os procedimentos metodológicos e éticos adotados. A partir das respostas de "aceite" dos estudantes, iniciamos as fases de coletas de dados que foi dividida em três momentos: (1) antes do vestibular: condiçóes pessoais; (2) processo de vestibular e (3) permanência no curso superior. 


\section{Antes do vestibular: condições pessoais}

Os/as seis estudantes participantes da pesquisa relataram: (a) ter uma renda mensal de até três salários mínimos advinda, em alguns casos, da complementariedade do Benefício de Prestação Continuada; (b) ser um dos poucos ou o único da família que chegou ao ensino superior e (c) ter que sair do interior para morar na capital em busca de oportunidade de estudo. Fabiana foi a única estudante dos seis participantes que teve a influência da mãe (formada em Pedagogia) para seguir carreira universitária. Bruno e Francisco são filhos de pais analfabetos. Os pais de Josefa, Mel e Carlos estudaram até a educação básica.

Os relatos dos estudantes revelam que apesar da ausência de casos de familiares que seguiram carreira universitária, o incentivo e a pressão, sobretudo das suas mães foram decisivos para eles e elas buscarem na educação a promessa de "ter um futuro melhor", conforme indicam suas vozes:

\footnotetext{
"Sair de casa e ter que ficar longe da família é sempre uma decisão muito difícil, mas eu precisava vir para cá para estudar (...) e minha mãe reforçava isso". (Bruno).

"O estudo foi uma maneira de eu me reintegrar à sociedade depois do meu acidente que me deixou com uma deficiência física. A família incentivou e me ajudou a voltar a estudar”. (Josefa).

"Lembro que eu gostava muito de jogar bola, mas minha mãe dizia pra eu buscar fazer uma coisa melhor, que me desse uma vida melhor no futuro. Hoje eu vejo que ela estava certa”. (Carlos).

"Minha mãe sempre me incentivou a aprender, por isso ela me matriculou numa escola pública junto com meus irmáos. Depois, tive que trabalhar para pagar o cursinho para tentar o vestibular". (Mel).

"Eu vim pra cá para estudar no Instituto dos Cegos. Meus irmãos também vieram (...). Eles também têm deficiência visual e a família sempre alertava que aqui na capital teríamos mais chance de estudar". (Francisco).

"Minha mãe é quem sempre me apoiou na escola e me apoia aqui. Só posso continuar no curso porque ela me ajuda todo dia a caminhar aqui dentro". (Fabiana).
}

Romper com o 'destino' do clá, de não-acesso à universidade, traçado exclusivamente para membros de camadas populares (ZAGO, 2006), desconstruir o imaginário coletivo e próprio de estigma da discapacidade (FERREIRA, 2004, SOARES, 2010) que impóe às pessoas com deficiência limitadas chances educacionais e ter que ser sucessivamente resiliente (FARIAS, 2011), são aspectos que configuram a experiência dos participantes desta pesquisa. A primeira etapa da entrevista foi importante para esta investigaçáo porque possibilitou conhecer os elementos que antecedem ou influenciaram o ingresso dos participantes. A acessibilidade à/na educação superior, portanto, deve ser analisada de maneira transversal, nas diferentes dimensóes da experiência porque começa bem antes da pessoa com deficiência prestar o vestibular e, por isso, deve incluir as oportunidades educacionais na infância, a efetivação de 
políticas públicas específicas (ONU, 2006), o acesso a cotas de ingresso e a assistência socioeconômica.

O acesso aos dados biográficos dos participantes ajuda a entender os riscos de assumir o discurso da meritocracia na educação superior (RODRIGUES, 2006) porque este reduz indiscriminadamente o ingresso a esta etapa de escolarizaçáo aos casos de êxito que limitam a experiência a esfera individual e pedagógica. Em outras palavras, é necessário explicitar o significado por trás da ideia de ascensão educacional, pois “o acesso à educação superior vai muito além da chamada 'eleição' individual quando as condiçôes de inserção é de sobrevivência no sistema educacional” (ZAGO, 2006, p. 228). Por certo, os seis estudantes com deficiência participantes são exceçóes em uma estatística bastante reduzida de jovens brasileiros que conseguem chegar à educação superior e, principalmente, quando se trata de pessoas com deficiência.

A formação em um curso superior para pessoas com deficiência que vêm de classe popular (ZAGO, 2006) vai além da perspectiva de melhorar a condição socioeconômica, mas representa também a chance de provar a capacidade intelectual de um grupo que historicamente foi estigmatizado pelo rótulo da incapacidade (FARIAS, 2011). A ideia de ocupar espaços de excelência e um posto profissional, que geralmente são de privilégio das pessoas sem deficiencia, contribui para romper com o estigma da incapacidade e abrir oportunidade de atuaçáo para outras pessoas com deficiência. No entanto, chegar à universidade ainda é uma exceçáo para este grupo e por isso os participantes relataram a inescapatória necessidade de enfrentar barreiras para ingressar e permanecer no curso superior.

\section{Processo de vestibular}

Mel prestou seu primeiro vestibular em 2003. Ela conta que nesta época não havia cadastro de reserva de vagas para as pessoas com deficiência; não existia serviço de tradução em Língua de Sinais durante as provas e também a correção não incluía a atenção profissional a resposta de um candidato surdo. Assim, Mel teve que concorrer em um exame sem qualquer tipo de ajustamento (ONU, 2006):

"No meu primeiro vestibular eu fui mal na redação, meu Português foi muito ruim. Quando vi o resultado eu procurei a coordenação para saber onde eu errei. A mulher falou: "seu Português foi ruim". Eu queria saber se quem corrigiu minha prova foi uma pessoa que entendesse o Português do surdo, porque é diferente do de uma pessoa ouvinte e na prova é preciso ver isso. Eu não entendo porque eles não liberam a Libras nas provas. As provas deveriam ser feitas em Libras para nós. Aprender a Libras mudou minha vida. Os surdos têm direito de ter um vestibular acessível, porque em Português é muito diferente e dificultam muito os textos longos". (Mel).

Assim como Mel, Carlos se sentiu prejudicado por não encontrar um vestibular acessível para ingressar no curso de Física:

\footnotetext{
"Nas provas do vestibular falta a projeção em Libras. O que é escrito em Português é muito diferente daquilo que está em Libras.
} 
Tem palavras que eu não conheço em Português e isso impede a compreensão do texto. A gramática eu acho fácil, os verbos, frases curtas (...) mas quando são textos longos, é difícil, complica muito a questão". (Carlos).

Quando decidiu prestar o vestibular, Bruno relatou que estava ciente dos obstáculos que encontraria desde o momento da inscrição:

\begin{abstract}
"Tive que recorrer ao apoio de um professor da escola regular para me inscrever no vestibular pelo site da universidade que não tinha acessibilidade para um candidato cego". (Bruno).
\end{abstract}

Ele acrescenta:

"Eu sabia de muitas questóes do vestibular e achei a prova ótima, mas achei que a questão da acessibilidade deixou a desejar, pois havia questôes que exigiam minha interpretação de figuras e gráficos. Mesmo quando o ledor de prova descrevia, se perdia muito e eu tinha dúvida, pois a questão só dependia das figuras para a resposta”. (Bruno).

Mesmo com as barreiras na seleção do vestibular, os estudantes conseguiram ser aprovados nos exames e essa aprovaçáo foi festejada por eles. Os participantes relataram que a oportunidade de ingressar na universidade os deixaram motivados. No entanto, a mescla de contentamento e decepção apareceu nos relatos porque já nas primeiras semanas do curso os estudantes identificaram diversos obstáculos na formação universitária.

Pode-se dizer que a seleção do vestibular não é planejada para o candidato com deficiência, mas sim construída com base na ideia de candidato normal, o sem deficiência. Essa determinação pedagógica é resultado da corponormatividade (MELLO, NUERNBERG, 2012) que é um valor cultural que regula a vida em geral a partir de padrôes físicos, cognitivos e comportamentais, inclusive nos espaços educacionais, adequando as pessoas com deficiência às normas sociais construídas pelas e para pessoas sem deficiência. Esta tendência reforça que as pessoas com deficiência são anormais e por isso são elas que necessitam se ajustar ao meio (WOODWARD, 2000), como vemos nos relatos de Mel, Carlos e Bruno ao não encontrarem acessibilidade nas provas do vestibular.

Mel afirma que buscou a coordenação para saber "onde errou" e que seu "Português foi muito ruim", estendendo a falta de acessibilidade da prova a sua capacidade intelectual. Esta internalização sobre o valor de seu desempenho, de perceber em si uma possível falta, é resultado da normatização que desconsidera outras formas de expressão de aprendizagem e categoriza as pessoas com deficiência como desviantes (WOODWARD, 2000; SILVA, 2000). Por isso, para candidatos com deficiencia, o vestibular, tal como é construído, representa uma barreira de acesso à educação superior, porque a seleção não é realizada com base na diversidade de estilos, modelos e expressões de aprendizagem e não inclui nas provas as variaçóes visuais, auditivas e sinestésicas de candidatos com deficiência. 


\section{Permanência no curso superior}

Unanimemente, os estudantes com deficiência destacaram surpresa e insegurança dos docentes ao perceberem sua presença na sala de aula. Segundo Bruno, os professores:

"Não são avisados e parecem desestabilizados ao saber que estamos matriculados na sua disciplina”. (Bruno).

Mel sente que a maioria dos docentes não a "aceita" como aluna da disciplina:

"No primeiro período do curso eu ouvi a seguinte frase de um professor: "O que você está fazendo no curso de Ciências da Computação? Este curso não é para você! Vá procurar alternativas de curso, como Libras, Pedagogia”. Ao invés de ele me dar força e me incentivar ele me tratou desta maneira (...) sua atitude me deixou muito triste". (Mel).

No dia do uso da técnica shadowing, presenciamos uma docente chamando a atenção de Mel perante os colegas de sala. Ela disse à estudante:

"É pra você ter mais atenção nas aulas, porque já tem dificuldade, por isso deve sentar sempre na frente e buscar compreender o conteúdo". (Comentário da professora de Mel no dia da técnica shadowing).

O comentário da professora assume a surdez como sinônimo de dificuldade de aprendizagem. Esta crença é gerada pelo modelo médico-patológico da deficiência que vê o problema na pessoa com deficiência e não nas barreiras externas (FERREIRA, 2004; ONU, 2006). Esta percepçáo se constitui como uma barreira atitudinal que não questiona a falta de tradutor intérprete de Libras e, nem tampouco, a postura didática inacessível da docente, mas a marca identitária ou a necessidade do estudante que é percebida como diferente das características dos demais (SILVA, 2014).

No caso de Bruno, mesmo sendo esportista de renome nacional em Judô e experiente com a prática de Educação Física, ele foi discriminado pelo docente na disciplina de Capoeira:

\footnotetext{
"Quando o professor se apresentou à turma e informou que a disciplina era quase toda prática, eu fiquei muito ansioso para cursar. Mas passaram-se três aulas e ele me deixava no canto. Foi quando me incomodei com aquilo e falei que eu queria participar. Nessa hora, ele disse que o curso de Educação Física não era um curso adequado para mim, e ainda me perguntou: "Você conseguiria ser aluno de um curso de Medicina ou Fisioterapia? Pois bem, aqui é do mesmo jeito, não é um curso pra você!"”. (Bruno).
}

Este foi apenas um exemplo de episódios consecutivos de discriminação que Bruno vivenciou nessa disciplina. Ao sentir que o professor estava violando o seu direito de participação e o discriminando em razão da deficiência (ONU, 2006), Bruno recorreu à ouvidoria da universidade para denunciá-lo, ação que não foi suficiente e o estudante teve que abrir um processo judicial. Até o último dia da coleta de dados o processo judicial ainda tramitava, chegando há três anos sem resoluçáo do caso. Por outro lado, a atitude de resistência e luta de Bruno, de levar o caso a instâncias jurí- 
dicas, revela o grau de consciência de seus direitos e de empoderamento (SOARES, 2010; DANTAS, 2011). Por suposto, tal atitude é adquirida tanto no processo de luta cotidiana da pessoa com deficiência que se vê na condição de constante necessidade de resistência e superação, como também por causa do gênero, por ser um homem que não aceita o tratamento discriminatório do professor ao colocá-lo numa posição de "menos másculo, fraco e dócil" (CARVALHO, ANDRADE, JUNQUEIRA, 2009, p. 7) em razão da sua deficiência.

No caso de Josefa, ela adquiriu a deficiência física em um acidente aos 16 anos. Perdeu a perna direita e por isso utiliza prótese e muletas. Para ir à universidade antes, ela dependia da ajuda da sua irmá que a levava de carro todos os dias, mas segundo Josefa:

$$
\begin{aligned}
& \text { "Eu chegava sempre atrasada e náo podia circular dentro da univer- } \\
& \text { sidade quando minha irmá ia embora". (Josefa). }
\end{aligned}
$$

Para permanecer no curso e ganhar autonomia, mesmo contrariando sua família, Josefa teve a ideia de comprar uma moto. Escondido da família ela aprendeu a pilotá-la:

\footnotetext{
"Ninguém queria me ajudar a comprar a moto e aprender a conduzi-la. A única opção foi encontrar uma maneira de financiá-la e durante todas as manhãs, bem cedo, fui treinando, treinando escondido até conseguir conduzi-la. Todos ficaram surpresos com minha coragem". (Josefa).
}

Mais que um transporte, para Josefa, a moto significou acessibilidade e autonomia na sua formação universitária. Mesmo se considerando uma estudante proativa e empoderada (DANTAS, 2011; SOARES, 2010), Josefa vivencia na universidade situaçôes de discriminação e preconceito, muitas vezes, veladas. A estudante relatou que teve uma aula numa reserva florestal e por isso precisou caminhar por um longo tempo:

\footnotetext{
"Com muito esforço e ajuda de uma colega, participei da aula, mas não houve nenhuma preocupação da professora com a minha condiçáo e eu tive que buscar um jeito de participar mesmo com a prótese me machucando muito". (Josefa).
}

A barreira atitudinal somada à barreira pedagógica se manifesta até em situaçôes em que a acessibilidade pode ser facilmente fornecida. A aplicação do ajustamento razoável como preconizado na Convenção sobre os Direitos das Pessoas com Deficiência (ONU, 2006) é a resposta para a correção da inacessibilidade da aula na reserva florestal. Desta forma, a condição da aluna deveria ter sido considerada no planejamento da aula e com isso seriam estabelecidas estratégias didáticas eficientes para tornar a aula acessível.

Para Francisco, a maior barreira é a segregação. Ele se sente isolado, sobretudo, quando tem que realizar trabalhos em grupo e termina fazendo sozinho. O estudante conta que teve um sério problema pessoal e ao procurar a coordenação do curso de Pedagogia foi ignorado pelos funcionários que 
"Agiram com indiferença e fizeram-me ir a diferentes setores para resolver a situação, sem qualquer informação sobre como eu deveria proceder e qual o setor certo para eu resolver meu problema. Tive que caminhar por muitos ambientes da universidade e na maioria náo existia acessibilidade física”. (Francisco).

Todos os casos ilustram que a educação superior mantêm e cria em sua estrutura - administrativa, pedagógica, atitudinal, comunicacional, informacional e arquitetônica - a segregação e a discriminação contra as pessoas com deficiência. As barreiras educacionais que limitam as chances de desenvolvimento educacional deste grupo tem a ver com a percepção médico-patológica (OLIVER, 1983; FERREIRA, 2004) que torna invisível as capacidades e potencialidades das pessoas com deficiências, vistas como indivíduos incompletos e com menos valia (FERREIRA, 2004; SOARES, 2010; FARIAS, 2011). Os dados mostram que o modelo patológico individualiza a condiçấo de deficiência a uma tragédia pessoal (OLIVER, 1983) e por isso em plano subjetivo coloca a culpa na própria pessoa com deficiência por sua condição, eliminando, assim, a responsabilidade institucional e coletiva. No caso de Mel, por exemplo, seu professor a desestimou a permanecer no curso de Ciências da Computação, caso semelhante ao de Bruno no curso de Educação Física. Nenhum dos professores questionou-se sobre sua própria concepção de educação e sobre o direito que os estudantes têm de ter acesso à educação em condição de igualdade (BRASIL, 1988; ONU, 2006).

A maior parte dos relatos e das cenas presenciadas com a técnica shadowing descreve experiências de barreiras e inacessibilidades na formação superior de estudantes com deficiência. No entanto, houve situaçóes que indicam acessibilidade atitudinal e pedagógica experienciadas pelos participantes. Mel e Josefa afirmam que a oportunidade de participarem de grupos de investigação é uma experiência relevante na sua formação porque contribui para que se sintam mais seguras e a adquiram conhecimentos especializados nas suas áreas de interesse. Mel acrescenta que:

"É o projeto no laboratório de computação que me torna ativa, me faz pensar em que área irei me especializar quando concluir a graduaçáo (...) penso até em fazer mestrado e doutorado fora do país, em uma universidade para surdos que existe nos Estados Unidos. Meu orientador me estimula a continuar na carreira universitária e a investir na área de tecnologias digitais". (Mel).

$\mathrm{Na}$ mesma linha, Josefa se sente motivada como membro de um grupo de pesquisa, no qual participa há três anos:

"A professora me valoriza como membro importante e isto tem me motivado a gostar do curso de Pedagogia. Quando cheguei aqui não me identificava com essa profissão. Estar no grupo é importante porque pude aprender sobre meus direitos e lutar por eles junto com outras pessoas com deficiência que estáo aqui ou fora da universidade. Antes nem aceitar minha deficiência eu aceitava”. (Josefa).

Hoje Josefa é representante do movimento estudantil e participa do Diretório Acadêmico, organizando eventos e atividades universitárias. Diferentemente de Jose- 
fa e Mel que encontraram oportunidade de participação em grupos de investigação, Bruno relatou que necessita cumprir créditos extras obrigatórios em componentes curriculares flexíveis, mas não há acessibilidade informacional:

\footnotetext{
"Os murais de aviso são inacessíveis para os estudantes cegos e, muitas vezes, só aqui é onde se encontram toda as informaçóes sobre seleção de projetos acadêmicos. Creio que há também a falta de aceitação dos professores que abrem vagas para atividades de pesquisa ou extensão. Penso que eles acham que é um desafio trabalhar com um aluno cego". (Bruno).
}

Fabiana e Carlos também enfrentam barreiras na sua formação acadêmica: ela por ter que ir e vir em um ambiente cheio de superfícies irregulares e por isso precisa que a sua mãe a acompanhe todos os dias à/na universidade, e ele por ter que assistir aulas e permanecer na universidade sem a presença do intérprete de Libras, utilizando a estratégia de leitura labial. Apesar de não serem barreiras atitudinais diretas, essas situaçôes revelam a negligência institucional, pois as barreiras não são um resultado 'natural', mas sim consequência da omissão coletiva e da violação da legislaçáo de acessibilidade, como preconizado nos decretos n ${ }^{\circ}$ 5296/04 (BRASIL, 2004), $n^{\circ}$ 5626/05 (BRASIL, 2005) e na Convençâo sobre os Direitos das Pessoas com Deficiência (ONU, 2006).

É importante contextualizar que só no final do ano de 2014 a universidade investigada oficializou o comitê de inclusão e a Política Institucional de Acessibilidade, depois de quatro anos de tentativas. No período em que os dados foram colhidos (no ano de 2013), os estudantes com deficiência somente tinham acesso a serviços pontuais, individualizados e temporários, como por exemplo, o Projeto Aluno-Apoiador ${ }^{4}$, o núcleo de transcrição de Braille, o empréstimo de um notebook e a atuação de um intérprete de Libras para uma demanda de mais de 12 estudantes surdos 5 . Esse cenário revela que a acessibilidade é aplicada como uma assistência e não como um direito universal, por exemplo, com o empréstimo de notebook ao invés de um laboratório de informática com acessibilidade ou com o Projeto Aluno-Apoiador para tentar suprir a falta de intérprete de Libras ou metodologias de aprendizagem acessíveis.

Os 'remendos' como soluçôes de acessibilidade não garantem os direitos das pessoas com deficiência e podem ser resultado da própria interpretação da lei. $\mathrm{O}$ uso das expressões "preferencialmente" (BRASIL, 1996), "quando possível" (BRASIL, 1961), "especialmente" (BRASIL, 1996, 2000, 2004, 2008, 2011) e "razoável" (ONU 2006, BRASIL 2009) cria brechas que permitem o fornecimento do mínimo e, muitas vezes, a negligência e a violação do direito à acessibilidade em âmbito institucional. O fato do comitê e da política de acessibilidade terem levado quase quatro anos para ser oficializados é um sinal de que predomina no imaginário coletivo da universidade a concepção patológica e fatalista da deficiência (OLIVER, 1983), que não considera as pessoas com deficiência como sujeitos de direitos, mesmo quando há uma vasta legislaçáo específica para este grupo e financiamento direto para acessibilidade nas universidades. 


\section{Conclusões}

Esta pesquisa teve como objetivo analisar a acessibilidade e inacessibilidade na experiência universitária de estudantes com deficiência. Os dados apresentados ilustram uma realidade muito mais ampla e complexa vivida pelas pessoas com deficiência nos cursos superiores. As experiências dos participantes desta pesquisa indicam que a acessibilidade é multidimensional porque inclui diferentes elementos da vida universitária como aspectos atitudinais (por exemplo: comportamento, reações), aspectos pedagógicos (por exemplo: metodologia de aprendizagem, didática, planejamento da aula, predisposição docente para incluir), aspectos informacionais e comunicacionais (por exemplo: acesso à informação acessível que circula no campus, serviço de tradução de Libras) e aspectos arquitetônicos (por exemplo: eliminação de obstáculos físicos, organização acessível dos mobiliários).

As barreiras atitudinais aparecem como as mais emergentes porque elas impedem a efetivação dos outros tipos de acessibilidade, por exemplo, quando há indisposição do docente (barreira atitudinal) em planejar aulas que considerem a participação do estudante com deficiência, consequentemente este estudante encontrará barreira pedagógico-curricular e, como nos casos aqui apresentados, para permanecer no curso terá que se adequar à aula inacessível, como se sua deficiência fosse uma "tragédia pessoal" (OLIVER, 1983). Dessa forma, esse desencadeamento é determinante para o registro de poucos casos de êxito quando se trata de acessibilidade. Nesta pesquisa, somente Josefa e Mel relataram experiências de acessibilidade atitudinal na relação com dois docentes que lhes oportunizaram a participação no grupo de pesquisa e extensão.

As experiências dos estudantes com deficiência revelam que a cultura universitária cria ambientes incapacitantes para as pessoas com deficiência. Por isso, as condições de acessibilidade ainda são incipientes e eles cotidianamente têm que encontrar alternativas para superar todo tipo de barreiras e inacessibilidades. A prorrogação na efetivaçáo do comitê e da política de acessibilidade tem várias consequências na formação dos estudantes com deficiência, como a falta de fiscalização de execução da legislação de acessibilidade dentro da instituição educacional investigada.

A negligência institucional e coletiva é resultado da cultura de descrença na capacidade das pessoas com deficiência e da invisibilidade social deste grupo (FERREIRA, 2004; SOARES, 2010). Esses aspectos consolidam fronteiras visíveis, como barreiras arquitetônicas, ou fronteiras invisíveis, como a não-oportunidade de participação nas aulas em razão da baixa expectativa docente. Portanto, o estigma patológico da deficiência desloca este grupo a um lugar ilhado no espaço comum, contornado pelas barreiras no ambiente e na convivência entre pessoas com e sem deficiência.

Para superar a percepçáo limitada sobre as pessoas com deficiencia, é necessário investir no modelo social da deficiência (OLIVER, 1983; FERREIRA, 2004). A contribuição deste modelo na aplicabilidade das leis de acessibilidade na educação superior está na conscientização coletiva (ONU, 2006), para a sistemática eliminação de barreiras que estão externa a pessoa com deficiência e na contestação da ideia de normalidade que as colocam em posição de sujeitos desviantes (WOODWARD, 
2000; SILVA, 2000). O modelo social da deficiência ajuda a compreender a acessibilidade muito mais que um direito, mas como um valor cultural associado a um movimento pessoal-coletivo de busca por atitudes favoráveis que equilibrem diferenças humanas e inerentes liberdades.

Somente no paradigma social é que a acessibilidade - como mudanças externas e eliminação de barreiras - é reivindicada e reforçada. Assim, o ingresso e a permanência de estudantes com deficiência passam a ser visto como um compromisso coletivo, contrário a lógica fatalista e da própria estrutura universitária que restringe seus processos ao mérito e à individualização. Com esta pesquisa, espera-se motivar outros professores e investigadores a aprofundarem os conhecimentos sobre acessibilidade na educaçáo superior e contribuir com luta para a garantia do direito à educação com qualidade e sem discriminação em espaços de privilégio social como ainda é a educação superior no Brasil.

\section{Referências}

ALbino, I. B. Acesso e Permanência na Universidade Federal do Rio Grande do Norte sob o Ponto de Vista do Docente e do Estudante com Deficiência. 2010, 223f. Dissertação (Mestrado em Educação). Universidade Federal do Rio Grande do Norte, 2010.

BARDI, T. Q. Acessibilidade no meio urbano: um estudo de caso do Jardim Universitário em Maringá. 2012, 117f. Dissertação (Mestrado em Engenharia Urbana). Universidade Estadual de Maringá, 2012.

BRASIL. Constituiçáo da República Federativa do Brasil de 1988. Disponível em: <http://www.planalto.gov. br/ccivil_03/constituicao/constituicao.htm>. Acesso em: 29 jul. 2013.

BRASIL. Lei no 4.024 de 20 de dezembro de 1961. Disponível em: <http://www.histedbr.fae.unicamp.br/ navegando/fontes_escritas/6_Nacional_Desenvolvimento/ldb\%20lei\%20no\%204.024,\%20de\%2020\%20 de\%20dezembro\%20de\%201961.htm> Acesso em: 29 jul. 2013.

BRASIL. LDB 9.394, de 20 de dezembro de 1996. Disponível em: <http://portal.mec.gov.br/seed/arquivos/ pdf/tvescola/leis/lein9394.pdf > acesso em: 20 jul. 2015.

BRASIL. Lei 10.098, de 19 de dezembro de 2000. Disponível em: <http://www.planalto.gov.br/CCIVIL_03/ Leis/L10098.htm > acesso em: 20 jul. 2015.

BRASIL. Decreto $\mathbf{n}^{\circ} 5296$ de 02 de dezembro de 2004. Disponível em: <http://www.planalto.gov.br/ccivil_03/_ato2004-2006/2004/decreto/d5296.htm > acesso em: 20 jul. 2015.

BRASIL. Decreto ${ }^{\circ}$ 5.626, de 22 de dezembro de 2005. Disponível em: <http://www.planalto.gov.br/ccivil_03/_ato2004-2006/2005/decreto/d5626.htm > acesso em: 20 jul. 2015.

BRASIL. Política Nacional da Educaçáo Especial na Perspectiva da Educaçáo Inclusiva. Portaria no 555/2007, prorrogada pela Portaria no 948/2007 [MEC/SEESP] de 7 de janeiro de 2008. <http://peei.mec.gov. br/arquivos/politica_nacional_educacao_especial.pdf > acesso em: 20 jul. 2015.

BRASIL. Decreto 6.949/09, de 25 de agosto de 2009. Disponível em: <http://www.planalto.gov.br/ccivil_03/_ato2007-2010/2009/decreto/d6949.htm > Acesso em: 15 mar. 2014.

BRASIL. Decreto $\mathbf{n}^{\circ}$ 7.611, de 17 de novembro de 2011. Disponível em: <http://www.planalto.gov.br/ccivil_03/_Ato2011-2014/2011/Decreto/D7611.htm> Acesso em: 03 jun. 2013.

BRASIL. Documento Orientador: Programa Incluir (2003). Disponível em: http://portal.mec.gov.br/index. php?option=com_docman\&task=doc_download\&gid=12737\&Itemid=. Acesso em: 03 jun. 2013.

BRASIL. IBGE. Censo Demográfico (2010). Disponível em: <http://www.ibge.gov.br/home/estatistica/populacao/censo2010/resultados_preliminares_amostra/default_resultados_preliminares_amostra.shtm >. Acesso em: 05 dez. 2016.

BRASIL. INEP. Censo da Educação Superior (2010). Disponível em: <http://download.inep.gov.br/educacao_superior/censo_superior/documentos/2010/divulgacao_censo_2010.pdf >. Acesso em: 05 dez. 2016. 
CARVAlHO, J. R. Acessibilidade e Locomoçáo da Pessoa com Deficiência e seus Direitos Constitucionais. 2012, 216f. Dissertaçáo (Mestrado em Sistema Constitucional de Garantia de Direitos). Instituição Toledo de Ensino, 2012.

CARVALHO, M. E. ANDRADE, F. C. B. JUNQUEIRA, R. D. Gênero e Diversidade Sexual: Um Glossário. In. Escolas Plurais. Editora UFPB, 2009.

COBOS, R. A. MORENO, A. M. Educación Superior y Discapacidad: Análisis desde la Experiencia de algunas Universidades Colombianas. Revista Espańola de Discapacidad. v. 2, n. 2, p. 83-101. 2014.

DANTAS, T. Jovens com deficiência como sujeitos de direitos: o exercício da autoadvocacia como caminho para o empoderamento e a participação social. 2011. 141f. Dissertação (Mestrado em Educação) - Universidade Federal da Paraíba, Paraíba, 2011.

LIPPO, H. (Org.). Sociologia da Acessibilidade e Reconhecimento Político das Diferenças. Canoas: Ed, ULBRA, 2012.

FARIAS, A. Q. Gênero e Deficiência: Vulnerabilidade Feminina, Ruptura e superação. 157f. Dissertação (Mestrado em Educação). Universidade Federal da Paraíba (UFPB) 2011.

FERNANDES, L. L. Gestáo do conhecimento em projetos de extensáo universitária direcionados às pessoas com deficiência. 2009, 302f. Tese (Doutorado em Engenharia). Universidade Federal de Santa Catarina, Santa Catarina: 2009.

FERREIRA, W. B. Invisibilidade, crenças e rótulos: Reflexão sobre a profecia do fracasso educacional na vida de jovens com deficiência. Disponível em: <www.federaçãoinddown.org.br> Acesso em: 04 mar. 2012.

GREGIO. L. F. A acessibilidade dos Objetos Educacionais de Física: Possibilidade para Pessoas com Deficiência Visual. 2011, 163 f. Dissertação (mestrado em educação). Universidade Estadual Paulista Júlio de Mesquita Filho. São Paulo, 2011.

JUNIOR, V. S. Política de Acessibilidade às Pessoas com Deficiência na Educaçáo Superior: Desdobramentos Jurídicos. 2012, 125f. Dissertação (mestrado em educação). Universidade Federal de Santa Maria, 2012.

JUNIOR, A. N. S. Juízes Leigos: um projeto e uma realidade no TJRJ1. In. Disponível em: <http://www. publicadireito.com.br/artigos/?cod=c80bcf42c220b8f5>. Acesso em: 04 fev. 2015.

LAMÔNICA, D. A. C. et al. Acessibilidade em Ambiente Universitário: Identificação de barreiras arquitetônicas no campus da USP de Bauru. In. Revista Brasileira de Educaçáo Especial, v. 14, n. 2, p. 177-188, maio-ago, 2008.

LUCK, M. ANDRÉ, M. Pesquisa em Educação: abordagens qualitativas. São Paulo: EPU, 1986.

MARTINS, D. S. Design de Recursos e Estratégias em Tecnologia Assistiva para Acessibilidade ao Computador e à Comunicaçáo Alternativa. 2011, $231 \mathrm{f}$. Dissertação (mestrado em Design). Universidade Federal do Rio Grande do Sul, 2011.

MAGRI, C. M. Avaliação da Acessibilidade e da Usabilidade de um Modelo de Ambiente Virtual de Aprendizagem para a Inclusáo de Deficientes Visuais. 2011, 96f. Dissertação (mestrado em Engenharia de Produção) Universidade de São Carlos, São Paulo, 2011.

MARGON, S. Acessibilidade e Inclusão Escolar no Ensino Agrícola: Um estudo de caso sobre as condiçóes de acessibilidade física com foco no aluno com deficiência visual no Instituto Federal de Educação Ciência e Tecnologia do Espírito Santo. 2012. 56f. Dissertação (Mestrado em Educação Agrícola). Universidade Federal Rural do Rio de Janeiro, 2012.

MCDONALD, S. Studying actions in context: a qualitative shadowing method for organizational research. In. Qualitative Research, v. 5, n. 4, p. 455-473, 2005.

MELO, I. S. C. Um estudante cego no curso de licenciatura em música da UFRN: Questóes de Acessibilidade Curricular e Física. 2011, 146f. Dissertação (mestrado em educaçáo). Universidade Federal do Rio Grande do Norte, 2011.

MELLO, A. G.; NUERNBERG, A. H. Gênero e Deficiência: interseçôes e perspectivas. In: Revista Estudos Feministas, Florianópolis - set.-dez. 2012, p. 635-655.

MELLO, A. G. FERNANDES, F. B. M. Guia de orientaçôes sobre gênero, deficiência e acessibilidade do Seminário Internacional Fazendo Gênero 10 (2013). Disponível em: <http://generoeciencias.paginas.ufsc.br/ files/2013/09/cartilha-on-line-final.pdf >. Acesso em: 05 de dez. 2016. 
MCRUER, R. Crip Theory: Cultural Signs of Queerness and Disability. New York: University. 2006.

OLIVEIRA, E. T. G. Acessibilidade na Universidade Estadual de Londrina: o ponto de vista do estudante com deficiência. 2003, 120, f. Dissertação (Mestrado em Educação). Universidade Júlio de Mesquita Filho/ Marília, 2003.

OLIVER, M. Social work with disabled people. London: MacMillan, 1983. Disponível em: <http://www. icjp.pt/sites/default/files/media/723-1116.pdf>. Acesso em: 20 out. 2013.

ONU. Convençáo sobre os Direitos das Pessoas com Deficiência (2006). Disponível em: <http://www. assinoinclusao.org.br/downloads/convencao.pdf>. Acesso em: 03 dez. 2011.

RODRIGUES, D. Inclusão e educaçáo: doze olhares sobre a educação inclusiva. São Paulo; Summus, 2006.

ROSA, A. R. MEDEIROS, C. R. JUNIOR, M. V. Sob as sombras do discurso colonial: subalternidade e configuraçôes de gênero em uma lavadeira do interior de Minas Gerais. In: Cad. EBAPE. BR vol.10 no.2 Rio de Janeiro, 2012. Disponível em: <http://dx.doi.org/10.1590/S1679-39512012000200009 > Acesso em 17 de jul. 2013.

SASAZAWA F. H. Ensino Superior e Educação Especial na Universidade Estadual de Maringá: Algumas Reflexôes. 2005, 112 f. Dissertação (Mestrado em Educaçáo). Universidade Estadual de Maringá, Paraná, 2005.

SANTOS, A. C. N. Acessibilidade de pessoas com deficiência física: o caso da Universidade Federal de Sergipe. 2012, 147f. Dissertação (Mestrado em Educação), Universidade Federal de Sergipe, 2012.

SILVA, J. S. S. Acessibilidade no Ensino Superior: Vozes de universitárias com deficiência sobre experiências de inclusão na Universidade Federal da Paraíba. 2011, 100f. Monografia (Licenciatura em Pedagogia) Universidade Federal da Paraíba, Joấo Pessoa: 2011.

SILVA, J. S. S. Acessibilidade, barreiras e superação: estudo de caso de experiências de estudantes com deficiência na educação superior. 2014, 242f. Dissertaçẫo (mestrado em educação) Universidade Federal da Paraíba: 2014.

SILVA, T. T. (org.) Identidade e Diferença: a perspectivas dos estudos culturais. Petrópolis, Vozes: 2000.

SOUZA, B. C. S. Programa Incluir (2005-2009): uma iniciativa governamental de educação especial para a educaçáo superior no Brasil. 2010, 233f. Dissertaçáo (Mestrado em Educaçáo), Universidade Federal de Santa Catarina, 2010.

SOARES, A. M. M. Nada sobre nós sem nós: formando jovens com deficiência para o exercício da autoadvocacia. 2010, 173f. Dissertação (Mestrado em Educação). Universidade Federal da Paraíba, João Pessoa: UFPB, 2010.

TAVARES, J. E. R. Hefestos: um modelo para suporte à acessibilidade Ubígua. 2011, 116f. Dissertação (mestrado em computaçáo aplicada). Universidade do Vale do Rio dos Sinos, 2011.

THERON, I. B. SAPPEY, J. R. The Methodological Identity of Shadowing in Social Science Research. In. Qualitive Research Journal. Vol. 12, p. 7-16. Bathurst, 2012. Disponível em: <http://www.emeraldinsight. com/doi/abs/10.1108/14439881211222697> acesso em: 04 fev. 2015

WOODWARD, K. Identidade e diferença: uma introdução teórica e conceitual. In: SILVA, Tomaz Tadeu (org.). Identidade e Diferença: A perspectiva dos estudos culturais. Petrópolis: Vozes, 2000. P. 16-35.

ZAGO, N. Do acesso à permanência no ensino superior: percursos de estudantes universitários de camadas populares. In: Revista Brasileira de Educaçáo, v. 11 n. 32 maio/ago/ 2006. p. 226-370.

\section{Notas}

\footnotetext{
${ }^{1}$ Associação Nacional de Pós-Graduação e Pesquisa em Educação.

${ }^{2}$ Coordenação de Aperfeiçoamento de Pessoal de Nível Superior.

${ }^{3}$ Publicaçóes disponíveis online no período de junho de 2000 a julho de 2013.

${ }^{4}$ Este projeto seleciona bolsistas para atuarem como tutores de estudantes com deficiência em seus cursos superiores.

${ }^{5}$ Segundo a coordenadora, o comitê ainda não tinha o número total de estudante com deficiência matriculados nos cursos da instituiçấo investigada. Até o final da coleta de dados, o comitê estava identificando esses alunos 'um a um' a partir dos relatos da comunidade universitária.
} 


\section{Correspondência}

Jackeline Susann Souza da Silva - Rua Quatro de Outubro n. 836. Bairro: Cruz das Armas. CEP: 58085-480. João Pessoa, Paraíba, Brasil.

E-mail: jackelinesusann@gmail.com

Recebido em 20 de agosto de 2016

Aprovado em 08 de maio de 2017 